\title{
Atrioventricular block complicating acute streptococcal tonsillitis
}

\author{
JOSEPH CARACO, RON ARNON, ITAMAR RAZ \\ From the Department of Medicine B, Hadassah University Hospital, Jerusalem, Israel
}

SUMMARY A 38 year old woman presented with severe weakness, high fever, and sore throat. Physical examination showed follicular tonsillitis and bradycardia caused by a atrioventricular block. Within 24 hours a normal sinus rhythm was regained but slight transient ST-T changes compatible with myocarditis were evident. Throat culture grew Streptococcus haemolyticus group $\mathbf{A}$.

Myocarditis is associated with various infections. ${ }^{1}$ The involvement of the conduction system may cause disturbances such as first and second degree atrioventricular block and even complete heart block. $^{2}$ Different aetiological agents including viruses, spirochaetes, parasites, and bacteria can cause this severe complication. ${ }^{1-3}$

We report an instance of transient atrioventricular heart block in a patient with an acute streptococcal throat infection.

\section{Case report}

A 38 year old woman presented with a six hour history of severe weakness, fever of $39.5^{\circ} \mathrm{C}$, and sore throat. Physical examination showed an irregular pulse of 60 beats per minute. The tonsils were swollen, red, and covered with white exudate, and there was submandibular tender lymphadenopathy.

Requests for reprints to Dr Joseph Caraco, Department of Medicine B, Hadassah University Hospital, POB 12000, Jerusalem, Israel 91120.
The lungs were clear; a 2/6 systolic murmur was heard at the heart base. The liver and spleen were not enlarged, and there was no other lymphadenopathy.

Laboratory examination showed an erythrocyte sedimentation rate of $45 \mathrm{~mm}$ in the first hour; a haemoglobin concentration of $13.3 \mathrm{~g} / \mathrm{dl}$, white blood cell count $176000 \times 10^{9} / 1$, and platelet count of $380000 \times 10^{9} / 1$. Kidney and liver function tests were all normal. Repeated measurements of plasma creatine kinase were all within the normal range. The antistreptolysin $O$ titre rose from 160 units to 480 units and the test for $\mathrm{C}$-reactive protein was negative. Throat culture grew streptococcus haemolyticus group A. An electrocardiogram an hour after admission showed atrioventricular block alternating with runs of complete atrioventricular block (fig 1). The echocardiogram was normal. She was treated with penicillin $G$ ( 8 million units/day) and continuously monitored by electrocardiography.

Twenty four hours later normal sinus rhythm was restored but slight $S T$-T changes compatible with myocarditis developed (fig 2a). Two weeks later these changes had disappeared completely (fig $2 b$ ). A year later the patient was in good health.

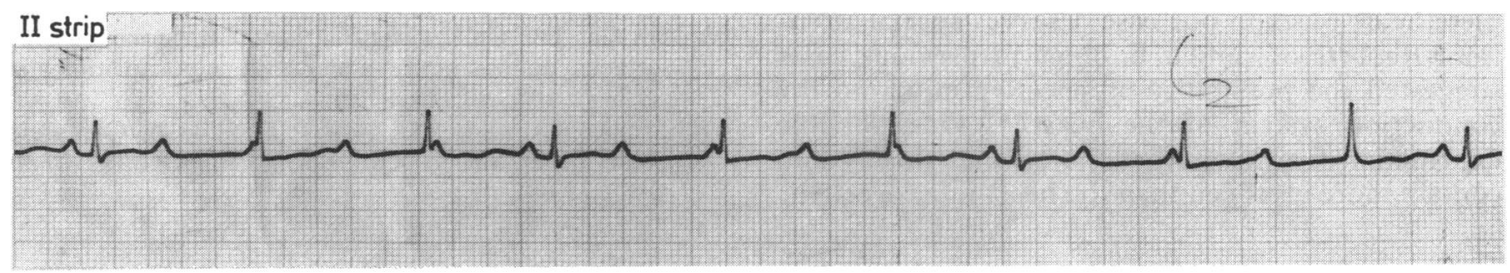

Fig 1 Electrocardiographic recording on lead II at admission showing atrioventricular block. 

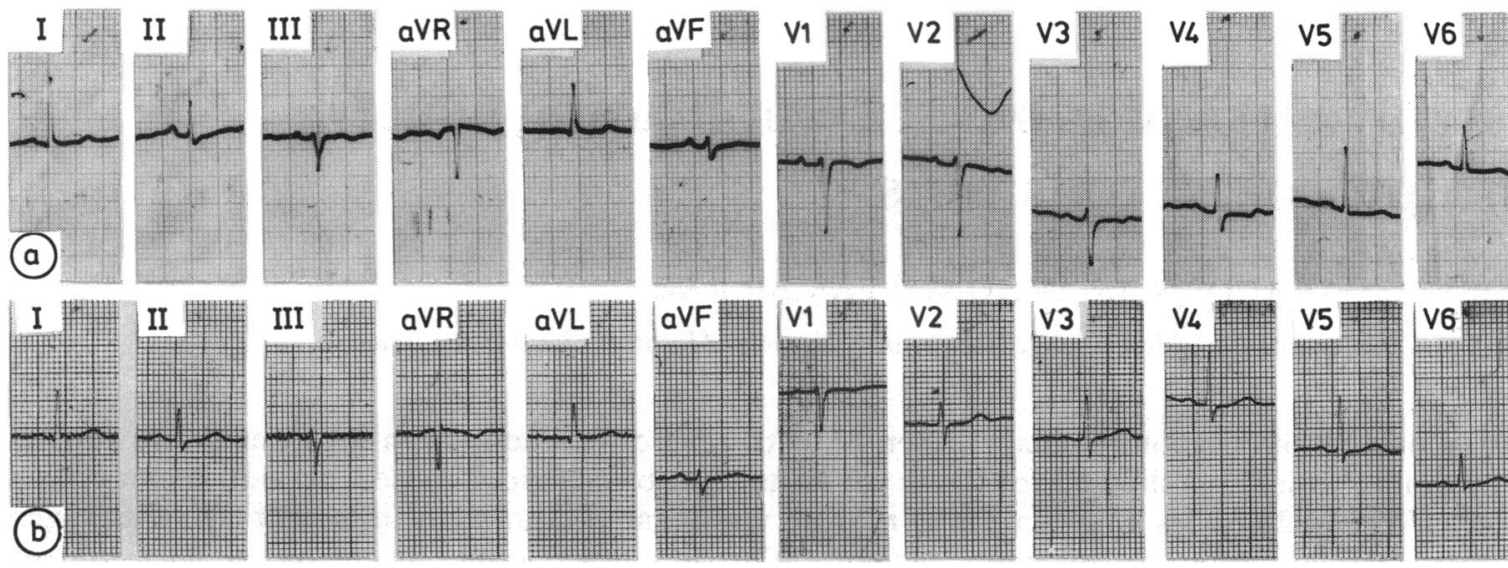

Fig 2 (a) Twelve lead electrocardiographic recordings 24 hours after admission showing normal sinus rhythm with ST-T changes consistent with myocarditis. (b) Twelve lead electrocardiographic recordings 14 days after admission.

\section{Discussion}

The association between streptococcal infection and cardiac damage in rheumatic fever is well known. There have been several studies of the incidence of myocarditis and conduction disturbances in the course of streptococcal tonsillitis or scarlet fever. Electrocardiographical changes compatible with myocarditis were seen in up to $39 \%$ of patients with scarlet fever. ${ }^{3-5}$ Only one case of complete heart block was reported among 2831 cases of scarlet fever. ${ }^{4}$ This prompted some workers to say that "the possibility of complicating rheumatic fever should be raised whenever conduction defect appears 2-3 weeks after the initiation of streptococcal infection". ${ }^{5}$

No atrioventricular conduction disturbances were found in 51 patients with an acute streptococcal infection. ${ }^{6}$ Only one case of complete heart block was reported in association with follicular tonsillitis and even in this patient the existence of occult rheumatic fever could not be ruled out. ${ }^{7}$ An additional five cases with complete heart block and a significant increase in antistreptolysin $\mathrm{O}$ titres were reported, but in these cases the clinical and bacteriological findings did not support the diagnosis of acute streptococcal infection. ${ }^{89}$

The discrepancy between the changes typical of mild myocarditis and the atrioventricular and complete heart block in our case deserves special attention. Reports of similar findings in previous cases suggested the possibility of selective injury to the conduction system of the heart ${ }^{689}$ One possible explanation for this is that the cells in this system contain more glycogen than the heart muscle cells.
The occurrence of rheumatic fever after streptococcal infection is usually attributed to allergic immunological reaction. Whereas the transient $\overrightarrow{\overrightarrow{0}}$ appearance of the myocarditis and atrioventricular $\varnothing$ heart block early in the course of infection in our case are more likely to be caused by a streptococcal toxin.

\section{References}

1 Wenger NK, Abelmann WH, Roberts WC. Myocarditis. In: Hurst JW, ed. The heart. New York: McGraw Hill, 1986:1158-80.

2 Davies MJ, Anderson RH, Becker AE. Conduction tissues in systemic disease. In: Davies MJ, Anderson $\mathrm{RH}$, Becker AE, eds. The conduction system of the heart. London: Butterworths, 1983:252-80.

3 Shookhoff C, Taran LM. Electrocardiographic studies in infectious diseases. Am J Dis Child 1931;42:55468.

4 Levander-Lindgren $M$. Electrocardiographic studies in $ᄋ$ scarlet fever. Acta Paediatrica 1952;suppl 91:1-211.

5 Friedberg CK. The heart in infections. In: Friedberg $\mathrm{CK}$, ed. Diseases of the heart. Philadelphia and London: Saunders, 1966:1455-73.

6 Clarke M, Keith JD. Atrioventricular conduction in acute rheumatic fever. Br Heart J 1972;34:472-9.

7 Rantz LA, Spink WW, Boisvert PJ. Abnormalities in $\mathrm{C}$ the electrocardiogram following hemolytic streptococcus sore throat. Arch Intern Med 1946;77:66-79. 0

$8 \mathrm{Lim} \mathrm{Ch}$, Toh CCS, Chia BL, Low LP. Stokes Adams attacks due to acute nonspecific myocarditis. $\mathrm{Am} \stackrel{?}{?}$ Heart J 1975;90:172-8.

9 Kirmser R, Umback R, Rowett D, Ross A. Complete heart block due to acute nonspecific carditis. Chest 1977;71:682-4. 